\title{
Aging of Polyurethane Foam Insulation in Simulated Refrigerator Panels - Three-year Results with Third-Generation Blowing Agents
}

\author{
KENNETH E. WILKES, \\ DAVID W. YARBROUGH, \\ W. ALEX GABBARD, AND GARY E. NELSON \\ Oak Ridge National Laboratory \\ P.O. Box 2008 \\ Oak Ridge, Tennessee 37831-6092
}

and several potential replacements - HFC-134a, HFC-245fa, J. RICHARD BOOTH

Department of Chemical Engineering

Tennessee Technological University

Cookeville, Tennessee 38505

\begin{abstract}
Laboratory data are presented on the effect of constanttemperature aging on the apparent thermal conductivity of polyurethane foam insulation for refrigerators and freezers. The foam specimens were blown with HCFC-141b and with three of its potential replacements - HFC-134a, HFC-245fa, and cyclopentane. Specimens were aged at constant temperatures of $90 ? \mathrm{~F}, 40$ F, and -10 ?F. Thermal conductivity measurements were made on two types of specimens: fullthickness simulated refrigerator panels containing foam enclosed between solid plastic sheets, and thin slices of core foam cut from similar panels. Results are presented for the first three years of a multi-year aging study. Preliminary comparisons of measured data with predictions of a mathematical aging model are presented.
\end{abstract}

\section{INTRODUCTION}

Polyurethane foam insulation currently used in refrigerators and freezers in the United States is blown primarily with HCFC-141b. Because of its potential for depleting the ozone layer, the Montreal Protocol mandates that domestic production of HCFC-141b cease by the end of 2002, requiring that a replacement blowing agent be used after that time. Since 1993, the Oak Ridge National Laboratory has been cooperating with the Appliance Research Consortium on studies of the aging characteristics of polyurethane insulation foamed with various blowing agents. The early studies were aimed at the replacement for CFC-11, and results of aging studies on simulated refrigerator panels blown with CFC-11, HCFC-141b, and a blend of HCFC-142b and HCFC-22 have been reported previously [1,2]. A long-term study is currently underway on aging of foam blown with HCFC-141b and cyclopentane. Tests with these third-generation blowing agents started in the fall of 1997 and are planned to continue for the next few years. Results on full-thickness specimens after aging at controlled temperatures for six months, one year, and two years have been reported previously [3-5]. The purpose of this paper is to present an update on this study by including results after three years of aging.

\section{SPECIMENS}

Two types of specimens are being studied. Specimens of one type were fabricated as panels that simulate the construction of a door or wall of a refrigerator. The panels are about two inches thick and have lateral dimensions of 24 inches by 24 inches. The faces of the panels are bounded on both sides by 0.04 in. thick plastic sheets, with separate sets of panels being made with acrylonitrile-butadiene-styrene (ABS) and high-impact-polystyrene (HIPS) plastic. The 0.04 in. thickness was considered to be representative of current refrigerator production, and plastic was used on both sides to accelerate the aging experiments by allowing gases to permeate through both sides of the panels. It was felt that the effect of an impermeable steel sheet on one side could be simulated using models that are being developed. The edges of the panels were sealed with aluminum foil tape to simulate the configuration in a refrigerator where there are no comparable cut exposed foam edges.

The panels were foamed with HCFC-141b (to provide the base case), HFC-245fa, HFC-134a, and cyclopentane. At the present time, the latter two blowing agents are the only commercially available non-ozone-depleting replacements for HCFC-141b. HFC-245fa is currently available on a semicommercial scale. Commitments have been made to construct 
a plant to produce HFC-245fa, and commercial availability is expected in mid-2002. The panels were fabricated by four foam suppliers (denoted here as suppliers A, B, C, and D), with each supplier providing panels with each of the four blowing agents.

To provide a characterization of the foam itself, specimens were also made that consisted of core foam cut into 12 in. squares and sliced into thicknesses of about 0.4 and 1.5 inches. A stack of four of the 0.4-in.-thick slices made up one test specimen.

It should be noted that the foams made in 1997 with the alternative blowing agents may not have been optimized for thermal performance. Visual observations of the sliced specimens showed a very uniform fine cellular structure with HCFC-141b but the presence of many larger bubbles interspersed within the fine cellular structure was observed for the other blowing agents.

\section{EXPERIMENTAL PROCEDURES}

Thermal resistance measurements were made using heatflow-meter-apparatuses (HFMAs) that conform to ASTM C 518 [6]. Intervening layers of foam rubber were placed between the panel specimens and the hot and cold plates of the apparatus to eliminate any undesirable air gaps between the specimens and the plates and also to protect the plates from the rigid test panels. Thermocouples were taped directly to the faces of the panels so that the temperature differences across the test panels were measured directly. Since the measurements gave the overall thermal resistance of the center of the test panel, a small correction ( $<1 \%$ ) was made for the thermal resistance of the plastic sheets to obtain the apparent thermal conductivity of the foam insulation. Tests on the core foam specimens gave the apparent thermal conductivity directly. The interlaboratory precision of thermal conductivity data obtained using HFMAs is about 2$4 \%$ [6]. The precision is better for relative measurements using the same apparatus.

The specimens were stored in closed, constant temperature, atmospheric pressure aging chambers between HFMA tests. Aging temperatures of $90 ? \mathrm{~F}, 40 ? \mathrm{~F}$, and $-10 ? \mathrm{~F}$ were used in order to span most of the range of conditions to which the foam would be exposed in a refrigerator application. Thermal tests were performed at 45 ?F and $75 ? \mathrm{~F}$ mean temperatures, using a temperature difference of 40 ?F. Thermal measurements were made on the full-thickness panels soon after their fabrication and then at six-month intervals. Since the slices of core foam aged much more rapidly than the full-thickness panels, more frequent thermal measurements were required. This limited the number of corefoam specimens that could be studied, and core-foam measurements were concentrated on specimens from Supplier A.

\section{RESULTS AND DISCUSSION}

\section{Core-Foam Specimens}

The thermal conductivity of freshly sliced foam at $75 ? \mathrm{~F}$ is shown in Table 1 for the two slice thicknesses. This shows that the lowest thermal conductivity was found with HCFC$141 \mathrm{~b}$, followed by HFC-245fa (4\% higher), cyclopentane $(13 \%$ higher), and HFC-134a (21\% higher). This relative ranking is the same as has been observed by Haworth [7]. Table 1 also shows that the thermal conductivity of thinner slices was consistently 3 to $4 \%$ higher than that of the thicker slices. This is at least partly due to the larger amount of damaged surface layers with the thinner slices where air immediately displaces the blowing agent in the cut cells. While the data for the thicker slices are more representative of that in the fullthickness panels, the thinner specimens age much more rapidly and are useful for comparing potential differences in long-term performance with the different blowing agents.

Curves of thermal conductivity versus time for the thinner (0.4 in.-thick) slices have been presented previously [5]. Figure 1 shows representative curves for aging at $40 ? \mathrm{~F}$ for the four blowing agents. The data were taken over a period of about two years. Since numerous previous studies have shown that the aging of unfaced foam scales with the square of the thickness (see [3] and ASTM C 1303 [8]), the data are plotted as thermal conductivity versus the aging time divided by the square of the slice thickness. With this scaling, data obtained over a time period of two years on slices 0.4 in. thick are good predictors of the variation of the thermal conductivity of unfaced 2 in.-thick specimens over a period of 50 years, well beyond the nominal refrigerator lifetime of 20 years.

The curves in Figure 1 show several trends. The curves show an initial rapid increase in thermal conductivity which is attributed to diffusion of air components into the cells of the foam, followed by a more gradual increase which is attributed to diffusion of the blowing agent out of the cells. Except for crossover of the curves for HCFC-141b and HFC$245 \mathrm{fa}$, the relative ranking of blowing agents given in Table 1 is preserved throughout the aging process. Data obtained at the other aging temperatures showed that the time required for a given change in thermal conductivity with aging at $40 ? \mathrm{~F}$

\begin{tabular}{|c|c|c|c|c|}
\hline Slice Thickness, in. & HCFC-141b & HFC-134a & HFC-245fa & Cyclopentane \\
\hline 0.4 & 0.132 & 0.160 & 0.138 & 0.150 \\
\hline
\end{tabular}


Thermal conductivity units are Btu•in./h•ft²?F. Each value represents an average over three specimens. Specimens are from Supplier A. 


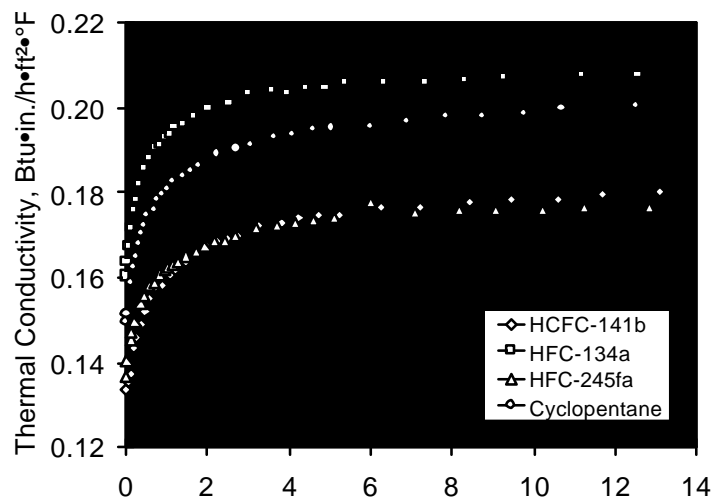

Time/Thickness ${ }^{2}$, years/in. ${ }^{2}$ (a) Aged at $40^{\circ} \mathrm{F}$; tested at $75^{\circ} \mathrm{F}$

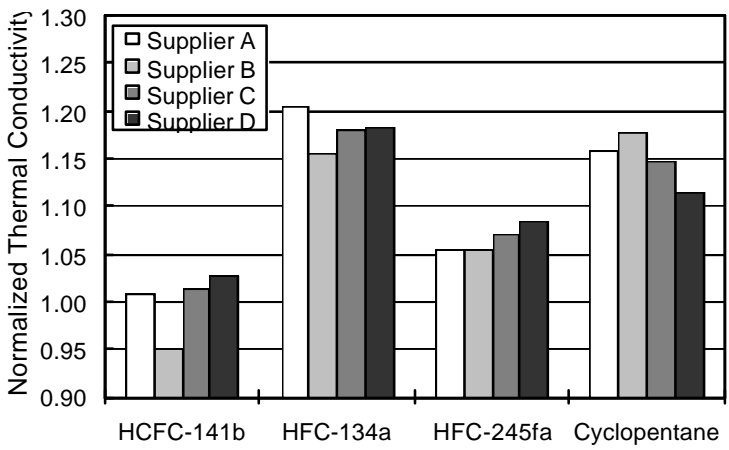

(a) Tested at $75^{\circ} \mathrm{F}$

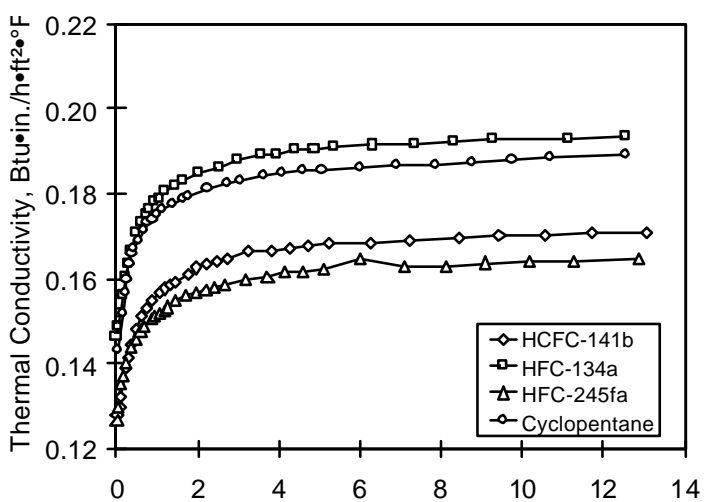

Time/Thickness ${ }^{2}$, years/in. ${ }^{2}$ (b) Aged at $40^{\circ} \mathrm{F}$; tested at $45^{\circ} \mathrm{F}$

Figure

1

Aging

of thin

(0. 4

in. -

thick)

core-

foam

speci

mens

blown

with

third-

gener

ation

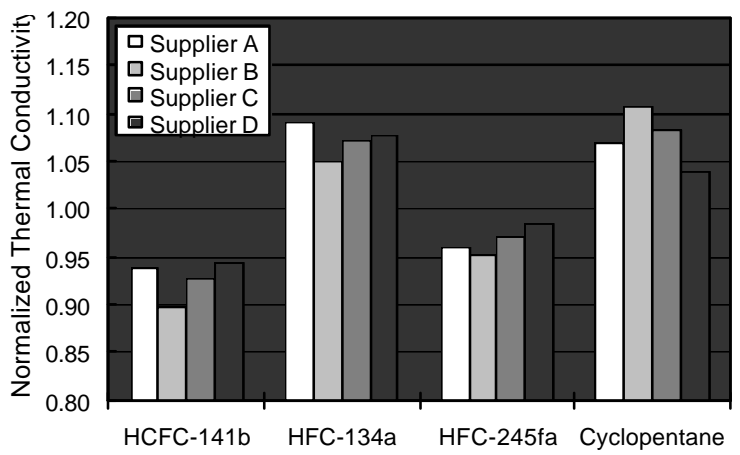

(b) Tested at $45^{\circ} \mathrm{F}$

blowing agents by Supplier A. Captions show aging and testing temperatures.

Figure 2. Average normalized thermal conductivity for full-thickness panels before aging. Data are normalized with respect to average for HCFC-141b tests at 75 ? F before aging.

was roughly twice as long as for aging at $90 ? \mathrm{~F}$, while the time required at -10 ? was about 10 times as long as at 90 ?F.[5]

Data read from curves such as in Figure 1 and companion data for the thicker (1.5 in.-thick) slices are compared with data obtained on full-thickness panels in the next section. In general, the data obtained on core-foam specimens may be 


\section{Full-Thickness Panels}

Thermal measurements on 96 full-thickness panels have been performed before and after aging under controlled temperatures for three years. Data on the panels are reported as normalized values because the directly measured values are biased due to the construction of the panels. From tests on standard reference materials, we have found that heat flows due to the aluminum foil tape around the panel edges change the measured center-of-panel thermal conductivities by a few percent. The data were normalized by averaging the pre-aging thermal conductivities measured at 75 ?F on the 24 panels that were blown with HCFC-141b, and then dividing the individual measured thermal conductivity values by this average. This normalization procedure was considered to be justified since the bias caused by the aluminum foil tape should be nearly the same for all panels tested.

Normalized results before aging and after aging for one and three years are given in Table 2. The results in the table give an indication of the variation in thermal conductivity among specimens from a particular supplier and among the four different suppliers. For example, the panels blown with HCFC-141b have pre-aging normalized conductivities at $75 ? \mathrm{~F}$ that range from 0.95 to 1.04 , but for a given supplier the variation is $2 \%$ or less. Similar levels of variation are seen for the other blowing agents.

Averaging the pre-aging data on the six panels for each supplier and each blowing agent gives the comparisons shown in Figure 2. On average, the $75 ? \mathrm{~F}$ thermal conductivity of foam blown with HFC-134a was about $18 \%$ higher than for HCFC-141b, while the conductivities for HFC-245fa and cyclopentane were about $7 \%$ and 15\% higher. For Supplier A only, the average conductivities for HFC-134a, 
and cyclopentane were $20 \%, 5 \%$, and $15 \%$ higher, were aged at $90 ? \mathrm{~F}, 40 ? \mathrm{~F}$, and $-10 ? \mathrm{~F}$ and tested at $75 ? \mathrm{~F}$. This

\begin{tabular}{|c|c|c|c|c|c|c|c|c|c|c|c|c|c|c|c|c|c|c|c|c|c|c|c|c|c|c|}
\hline \multirow{2}{*}{\multicolumn{27}{|c|}{ Values are normalized to the average of $t$}} \\
\hline & & & & & & & & & & 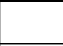 & & & & & & & & & & & & & & & & \\
\hline & & Aging & & & & & & & & & & & & & & & & & & & & & & & & \\
\hline Blowing & & Temp., & \multicolumn{12}{|c|}{ Tested at $75^{\circ} \mathrm{F}$} & \multicolumn{12}{|c|}{ Tested at $45^{\circ} \mathrm{F}$} \\
\hline Agent & Liner & ${ }^{\circ} \mathrm{F}$ & \multicolumn{3}{|c|}{ Supplier A } & \multicolumn{3}{|c|}{ Supplier B } & \multicolumn{3}{|c|}{ Supplier C } & \multicolumn{3}{|c|}{ Supplier D } & \multicolumn{3}{|c|}{ Supplier A } & \multicolumn{3}{|c|}{ Supplier B } & \multicolumn{3}{|c|}{ Supplier C } & \multicolumn{3}{|c|}{ Supplier [ } \\
\hline & & & $0 \mathrm{Yr}$. & $1 Y r$. & $3 Y r$. & $0 Y r$. & $1 Y r$ & $3 Y r$. & $0 Y r$ & $1 \mathrm{Yr}$. & $3 \mathrm{Yr}$ & $0 Y r$. & $1 \mathrm{Yr}$ & $3 Y r$. & $0 Y r$ & $1 \mathrm{Yr}$ & $3 \mathrm{Yr}$ & $0 \mathrm{Yr}$ & $1 Y r$ & $3 Y r$. & $0 Y r$. & $1 Y r$. & $3 Y r$. & $0 \mathrm{Yr}$. & $1 Y \mathrm{Yr}$ & $3 \mathrm{Yr}$. \\
\hline HCFC-141b & ABS & 90 & 1.01 & 1.06 & 1.17 & 0.95 & 1.00 & 1.11 & 1.03 & 1.09 & 1.21 & 1.04 & 1.09 & 1.22 & 0.94 & 0.97 & 1.07 & 0.90 & 0.92 & 1.05 & 0.93 & 0.98 & 1.11 & 0.95 & 0.99 & 1.12 \\
\hline HCFC-141b & ABS & 40 & 1.01 & 1.04 & 1.09 & 0.95 & 1.00 & 1.09 & 1.01 & 1.07 & 1.17 & 1.03 & 1.08 & 1.15 & 0.94 & 0.93 & 0.99 & 0.91 & 0.90 & 0.99 & 0.92 & 0.95 & 1.05 & 0.95 & 0.96 & 1.04 \\
\hline HCFC-141b & ABS & -10 & 1.01 & 1.02 & 1.03 & 0.95 & 0.96 & 0.97 & 1.02 & 1.06 & 1.07 & 1.04 & 1.05 & 1.06 & 0.94 & 0.93 & 0.94 & 0.89 & 0.88 & 0.90 & 0.93 & 0.93 & 0.95 & 0.95 & 0.94 & 0.95 \\
\hline HCFC-141b & HIPS & 90 & 1.01 & 1.13 & 1.25 & 0.95 & 1.06 & 1.16 & 1.01 & 1.18 & 1.29 & 1.02 & 1.19 & 1.31 & 0.94 & 1.04 & 1.15 & 0.90 & 0.99 & 1.09 & 0.93 & 1.07 & 1.19 & 0.94 & 1.10 & 1.21 \\
\hline HCFC-141b & HIPS & 40 & 1.00 & 1.06 & 1.14 & 0.95 & 1.01 & 1.11 & 1.01 & 1.13 & 1.24 & 1.03 & 1.11 & 1.24 & 0.94 & 0.97 & 1.06 & 0.90 & 0.92 & 1.03 & 0.93 & 1.02 & 1.13 & 0.94 & 1.02 & 1.14 \\
\hline HCFC-141b & HIPS & -10 & 1.01 & 1.03 & 1.04 & 0.95 & 0.95 & 0.98 & 1.01 & 1.07 & 1.12 & 1.02 & 1.05 & 1.09 & 0.94 & 0.94 & 0.96 & 0.90 & 0.88 & 0.91 & 0.93 & 0.96 & 1.01 & 0.94 & 0.95 & 0.99 \\
\hline HFC-134a & ABS & 90 & 1.21 & 1.26 & 1.37 & 1.17 & 1.23 & 1.33 & 1.17 & 1.25 & 1.36 & 1.18 & 1.25 & 1.35 & 1.09 & 1.13 & 1.25 & 1.07 & 1.11 & 1.22 & 1.06 & 1.12 & 1.24 & 1.08 & 1.13 & 1.24 \\
\hline HFC-134a & ABS & 40 & 1.20 & 1.23 & 1.31 & 1.14 & 1.19 & 1.23 & 1.17 & 1.24 & 1.29 & 1.19 & 1.23 & 1.28 & 1.09 & 1.10 & 1.18 & 1.04 & 1.05 & 1.10 & 1.07 & 1.10 & 1.16 & 1.08 & 1.10 & 1.15 \\
\hline HFC-134a & ABS & -10 & 1.21 & 1.22 & 1.25 & 1.16 & 1.18 & 1.19 & 1.18 & 1.22 & 1.24 & 1.18 & 1.22 & 1.23 & 1.09 & 1.09 & 1.12 & 1.05 & 1.06 & 1.07 & 1.07 & 1.09 & 1.10 & 1.08 & 1.10 & 1.10 \\
\hline HFC-134a & HIPS & 90 & 1.20 & 1.33 & 1.44 & 1.15 & 1.28 & 1.37 & 1.19 & 1.33 & 1.44 & 1.17 & 1.30 & 1.40 & 1.09 & 1.21 & 1.32 & 1.04 & 1.16 & 1.26 & 1.08 & 1.20 & 1.32 & 1.07 & 1.19 & 1.29 \\
\hline HFC-134a & HIPS & 40 & 1.21 & 1.27 & 1.35 & 1.14 & 1.20 & 1.27 & 1.18 & 1.27 & 1.35 & 1.18 & 1.24 & 1.31 & 1.09 & 1.13 & 1.22 & 1.04 & 1.07 & 1.15 & 1.08 & 1.13 & 1.22 & 1.08 & 1.11 & 1.18 \\
\hline HFC-134a & HIPS & -10 & 1.21 & 1.23 & 1.25 & 1.17 & 1.21 & 1.23 & 1.19 & 1.24 & 1.27 & 1.19 & 1.22 & 1.23 & 1.09 & 1.10 & 1.14 & 1.07 & 1.08 & 1.12 & 1.07 & 1.10 & 1.13 & 1.08 & 1.09 & 1.11 \\
\hline HFC-245fa & ABS & 90 & 1.06 & 1.10 & 1.16 & 1.04 & 1.07 & 1.16 & 1.07 & 1.12 & 1.21 & 1.09 & 1.13 & 1.22 & 0.97 & 0.98 & 1.07 & 0.95 & 0.96 & 1.06 & 0.97 & 1.00 & 1.10 & 0.99 & 1.02 & 1.11 \\
\hline HFC-245fa & ABS & 40 & 1.05 & 1.08 & 1.12 & 1.07 & 1.11 & 1.24 & 1.07 & 1.11 & 1.16 & 1.09 & 1.13 & 1.17 & 0.96 & 0.96 & 1.00 & 0.96 & 0.97 & 1.11 & 0.97 & 0.97 & 1.02 & 0.99 & 1.00 & 1.04 \\
\hline HFC-245fa & ABS & -10 & 1.06 & 1.06 & 1.08 & 1.04 & 1.06 & 1.16 & 1.07 & 1.10 & 1.11 & 1.09 & 1.12 & 1.13 & 0.96 & 0.96 & 0.97 & 0.94 & 0.94 & 1.05 & 0.96 & 0.97 & 0.98 & 0.99 & 1.00 & 1.00 \\
\hline HFC-245fa & HIPS & 90 & 1.05 & 1.15 & 1.21 & 1.05 & 1.13 & 1.22 & 1.08 & 1.18 & 1.28 & 1.08 & 1.18 & 1.27 & 0.96 & 1.04 & 1.10 & 0.94 & 1.01 & 1.12 & 0.97 & 1.07 & 1.16 & 0.98 & 1.07 & 1.16 \\
\hline HFC-245fa & HIPS & 40 & 1.06 & 1.11 & 1.17 & 1.05 & 1.09 & 1.17 & 1.08 & 1.14 & 1.21 & 1.08 & 1.15 & 1.21 & 0.97 & 0.99 & 1.06 & 0.95 & 0.96 & 1.05 & 0.97 & 1.01 & 1.09 & 0.99 & 1.03 & 1.09 \\
\hline HFC-245fa & HIPS & -10 & 1.05 & 1.08 & 1.09 & 1.08 & 1.31 & 1.43 & 1.07 & 1.11 & 1.12 & 1.09 & 1.11 & 1.13 & 0.96 & 0.97 & 0.98 & 0.98 & 1.20 & 1.32 & 0.97 & 0.99 & 0.99 & 0.98 & 1.00 & 1.01 \\
\hline Cyclopentane & ABS & 90 & 1.16 & 1.22 & 1.35 & 1.18 & 1.22 & 1.35 & 1.14 & 1.22 & 1.32 & 1.11 & 1.18 & 1.30 & 1.07 & 1.13 & 1.27 & 1.10 & 1.16 & 1.27 & 1.07 & 1.17 & 1.27 & 1.04 & 1.11 & 1.24 \\
\hline Cyclopentane & ABS & 40 & 1.16 & 1.19 & 1.28 & 1.18 & 1.21 & 1.26 & 1.14 & 1.21 & 1.26 & 1.12 & 1.16 & 1.23 & 1.06 & 1.07 & 1.17 & 1.10 & 1.12 & 1.19 & 1.07 & 1.11 & 1.18 & 1.04 & 1.05 & 1.13 \\
\hline Cyclopentane & ABS & -10 & 1.16 & 1.17 & 1.18 & 1.18 & 1.20 & 1.22 & 1.14 & 1.20 & 1.21 & 1.12 & 1.14 & 1.15 & 1.06 & 1.05 & 1.08 & 1.10 & 1.10 & 1.12 & 1.07 & 1.10 & 1.12 & 1.05 & 1.04 & 1.05 \\
\hline Cyclopentane & HIPS & 90 & 1.17 & 1.33 & 1.43 & 1.18 & 1.30 & 1.41 & 1.16 & 1.32 & 1.40 & 1.11 & 1.28 & 1.39 & 1.09 & 1.25 & 1.35 & 1.12 & 1.25 & 1.35 & 1.10 & 1.27 & 1.35 & 1.02 & 1.22 & 1.32 \\
\hline Cyclopentane & HIPS & 40 & 1.15 & 1.24 & 1.37 & 1.18 & 1.24 & 1.31 & 1.15 & 1.26 & 1.34 & 1.12 & 1.23 & 1.32 & 1.06 & 1.13 & 1.27 & 1.11 & 1.16 & 1.25 & 1.09 & 1.19 & 1.27 & 1.05 & 1.14 & 1.24 \\
\hline Cyclopentane & HIPS & -10 & 1.16 & 1.19 & 1.24 & 1.17 & 1.19 & 1.21 & 1.15 & 1.21 & 1.24 & 1.12 & 1.16 & 1.19 & 1.07 & 1.07 & 1.14 & 1.11 & 1.11 & 1.13 & 1.09 & 1.14 & 1.17 & 1.05 & 1.07 & 1.11 \\
\hline
\end{tabular}

respectively, than for HCFC-141b. These relative differences are in good agreement with the values given in Table 1 for the core foam, also from Supplier A. At the 45 ?F test temperature, the average conductivities for HFC-134a, HFC-245fa, and cyclopentane were $16 \%, 4 \%$, and $16 \%$ higher than for HCFC141b. The ordering of the blowing agents was nearly the same for all four suppliers. However, there were some slight differences. For Supplier B, the conductivity for cyclopentane was slightly higher than that for HFC-134a at both test temperatures. For Supplier C, the conductivity for HFC-134a was higher than that for cyclopentane at the 75 ?F test temperature, but was slightly lower at the 45 ?F test temperature.

Figure 3 shows the variation of normalized thermal conductivity with time for panels from Supplier A as they figure shows that the panels with ABS sheets aged less rapidly than did the panels with HIPS sheets, and that aging decreased with decreasing temperature, with only small changes at $-10 ? \mathrm{~F}$. In general, the relative ranking of the four blowing agents was maintained during aging over the three year period. Exceptions to this occurred for the panels aged at $90 ? \mathrm{~F}$, where the curves for HCFC-141b and HFC-245fa crossed, and also for the HIPS panels aged at $90 ? \mathrm{~F}$ and $40 ? \mathrm{~F}$ where the curves for HFC-134a and cyclopentane came together or crossed. Results for other suppliers were generally similar; however, certain details differed. For example, the pre-aging difference between HCFC-141b and HFC-245fa was larger for Supplier B than for Supplier A (see Figure 2), and the curves for these two blowing agents did not cross for Supplier B. 
Figure 4 shows percentage increases in thermal conductivity after three years of aging. These values were obtained by averaging the percentage increases for the four suppliers (except for HFC-245fa with HIPS at -10 ?F, where the anomalously high values for Supplier B were not included in the average). Percentage increases for 2 in.-thick core foam for Supplier A are also shown for comparison. The core foam values at three years and 20 years of aging were obtained by scaling the results for 1.5 in.-thick and 0.4 in.-thick core-foam specimens, respectively. The results show that the plastic sheets significantly reduce the rate of aging, with ABS being more effective than HIPS. The difference between HIPS and ABS is attributed to the higher gas permeances for HIPS. Figure 4 also shows that decreasing temperature results in decreases in the rate of aging, with the changes at -10 ? $F$ being very small. This behavior is similar to that observed for the core foam, and is attributed to the effect of temperature on the permeance of the plastic sheets, the coefficients of diffusion of gases through the foam, and the vapor pressure of the blowing agent. Both Figure 3 and Figure 4 show that the percent increases for HFC-245fa tend to be somewhat less than for the other blowing agents.

The data presented for the test panels should not be interpreted directly as quantitative indications of the changes that would be expected in the walls and doors of refrigerators. This is because only one surface in a refrigerator will have a plastic sheet, while the other surface will have an impermeable steel sheet, which would lower the aging rate of the panels.

\section{COMPARISON OF DATA WITH MODEL RESULTS}

Since aging data on the full-thickness panels are being collected on a real-time basis, there is a need for a model that can predict long-term aging behavior. A one-dimensional model for isothermal aging of foam panels with semipermeable surface sheets has been developed, and is being validated against the measured aging data. Preliminary results from the model are presented here.

\section{Description of Model}

The model is similar to those described in the literature for diffusion of gases through foam [e.g, 9]. However, we have added the effects of partial condensation of blowing agent within the foam cells. The transient distribution of a gas during aging is given by Fick's second law of diffusion:

$$
\frac{\partial E}{\partial t}=D \frac{\partial^{2} t}{\partial x^{2}}
$$

where $\mathrm{c}$ is the concentration of gas in moles per unit volume, $\mathrm{D}$ is the effective diffusion coefficient which is taken to be a constant, $\mathrm{t}$ is time, and $\mathrm{x}$ is distance. The gas concentration, $\mathrm{c}$, and pressure, $\mathrm{P}$, are related through the ideal gas law, $\mathrm{c}=$ $\mathrm{P} / \mathrm{RT}$, where $\mathrm{R}$ is the gas constant, and $\mathrm{T}$ is the absolute temperature. The foam is produced at relatively high temperatures, but the panels are being aged at lower temperatures, where a fraction of the blowing agent can be in a condensed state. In this case, it is assumed that the liquid is immobile and the only mechanism for transport of the blowing agent is by vapor diffusion. The vapor pressure curve provides an upper limit on the gas pressure, and a mass balance is added to track the distribution of liquid and vapor phases of the blowing agent.

The initial conditions for Equation 1 are that the concentrations of oxygen and nitrogen are zero, while the concentrations of carbon dioxide and blowing agent are uniform, with values that are provided by the foam supplier. Boundary conditions for Equation 1 are given by application of Fick's first law of diffusion:

$$
\pm D \frac{\partial \epsilon}{\partial x}=\boldsymbol{R}\left(\epsilon_{0}-c\right)
$$

where $\mathrm{K}$ is the permeance of a surface sheet $(\mathrm{K}=$ ? for bare cut foam, 0 for solid metal surface, and intermediate values for plastic sheets on the surface), $c_{0}$ is the concentration of gas in the space surrounding the panel, $\mathrm{c}$ and the derivative are evaluated at the interface between the foam and the 


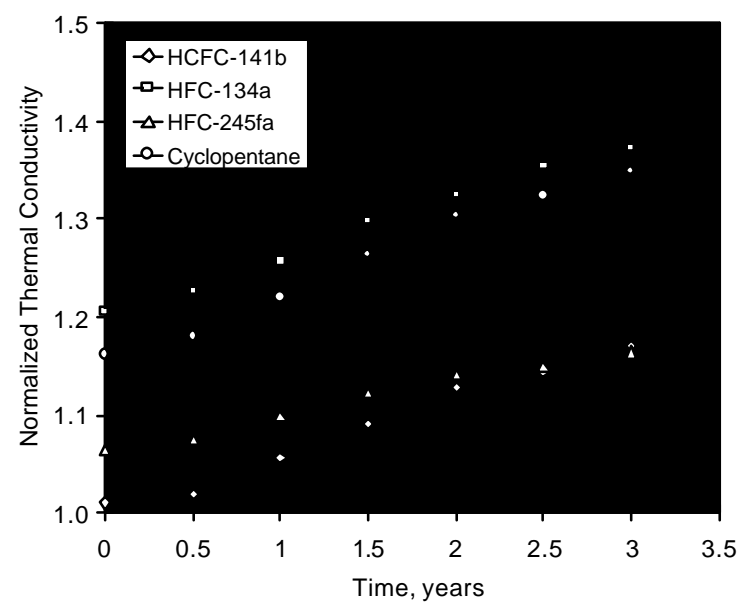

(a) ABS; Aged at $90^{\circ} \mathrm{F}$

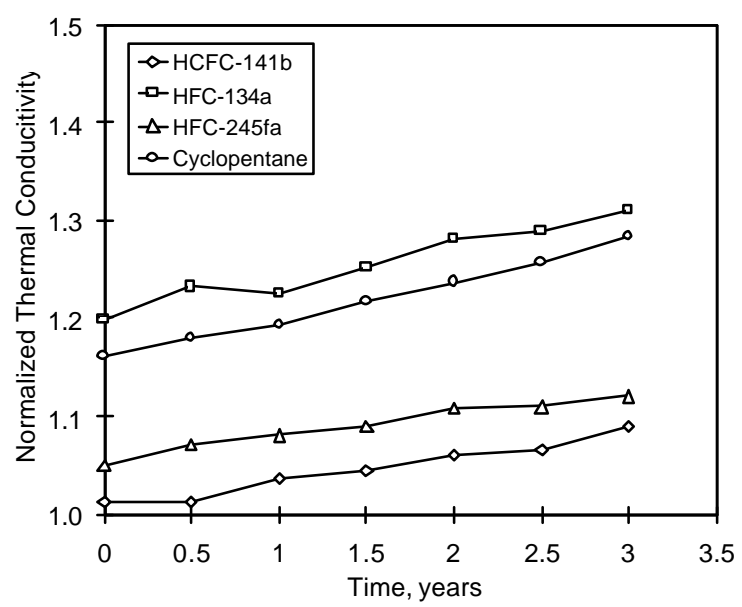

(c) ABS; Aged at $40^{\circ} \mathrm{F}$

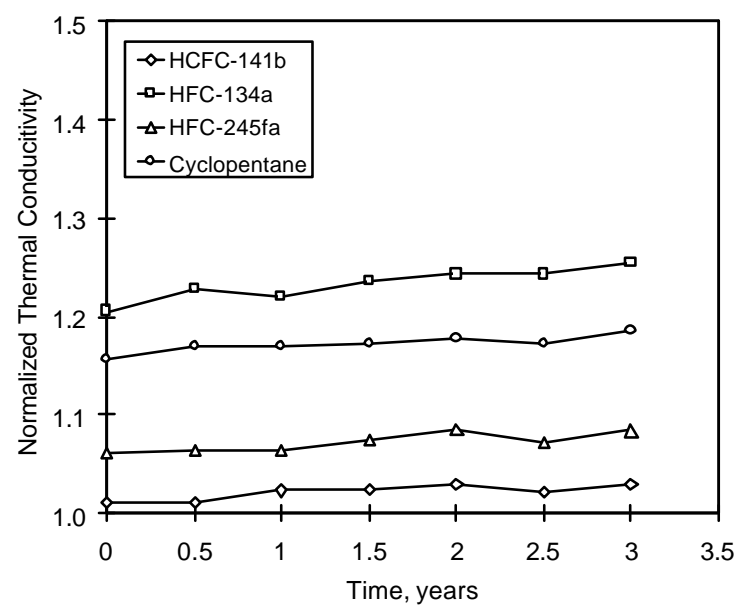

(e) ABS; Aged at $-10^{\circ} \mathrm{F}$

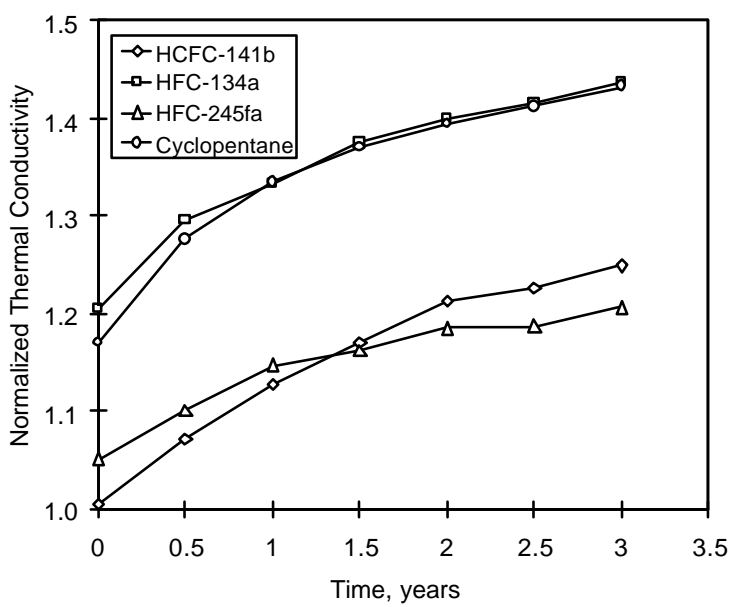

(b) HIPS; Aged at $90^{\circ} \mathrm{F}$

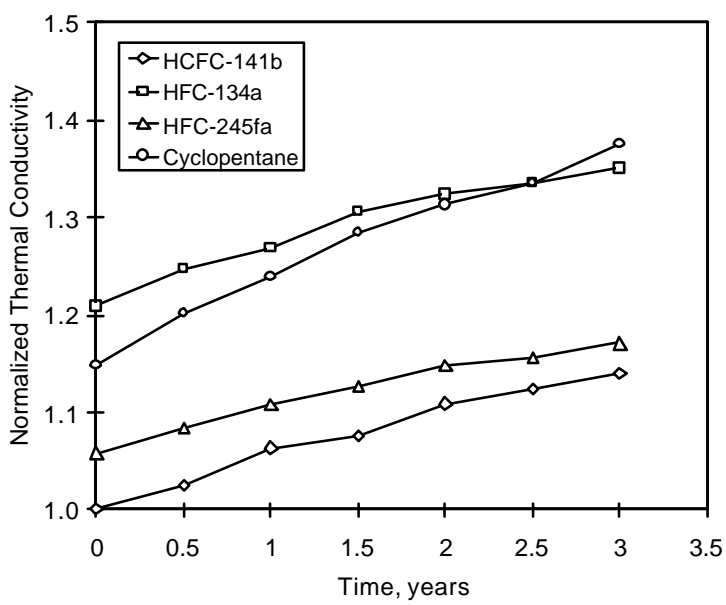

(d) HIPS; Aged at $40^{\circ} \mathrm{F}$

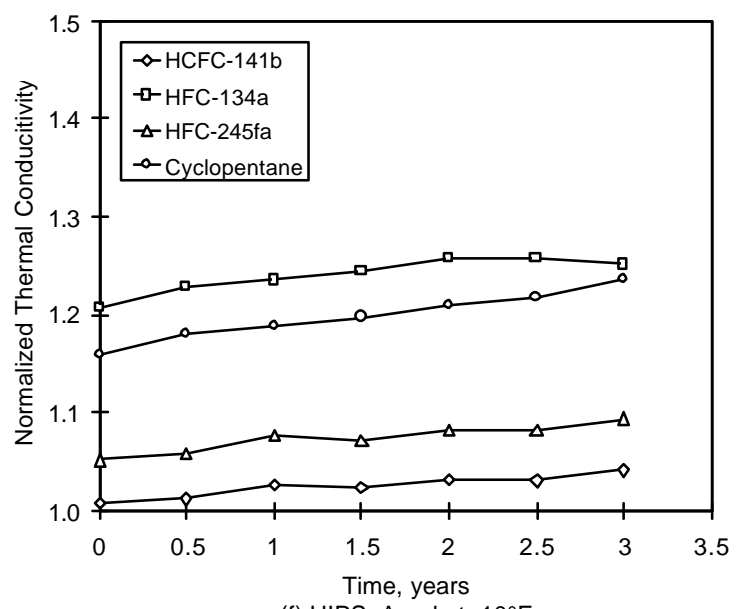

(f) HIPS; Aged at $-10^{\circ} \mathrm{F}$

Figure 3. Aging of foam in full-thickness panels blown with third-generation blowing agents by Supplier A. Tested at 75?F. 


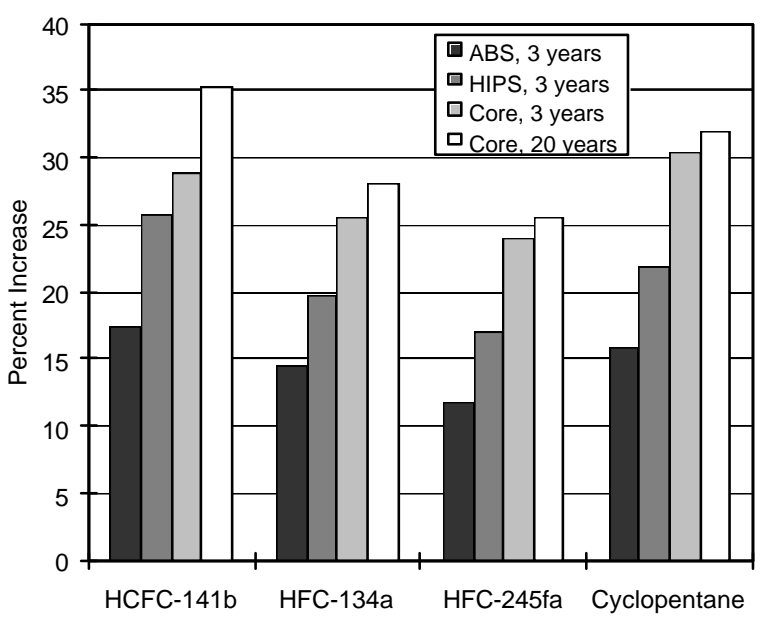

(a) Aged at $90^{\circ} \mathrm{F}$; tested at $75^{\circ} \mathrm{F}$

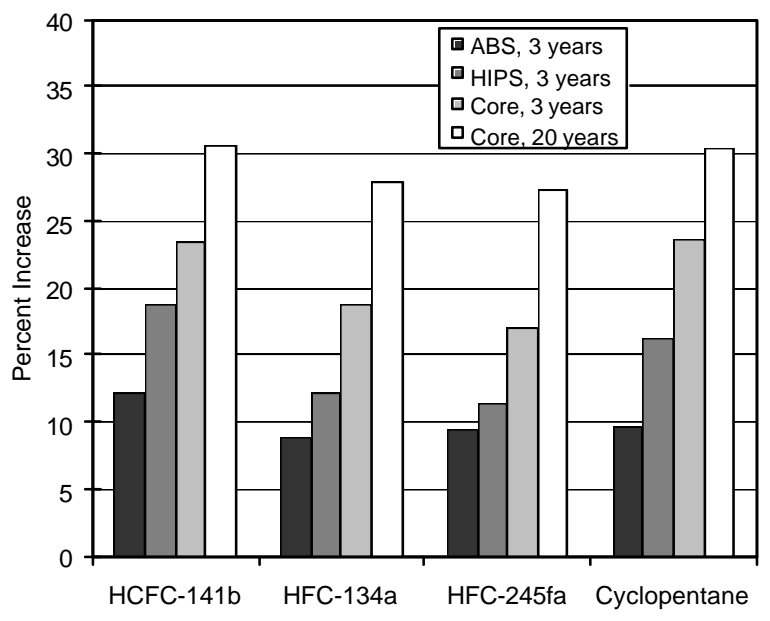

(c) Aged at $40^{\circ} \mathrm{F}$; tested at $75^{\circ} \mathrm{F}$

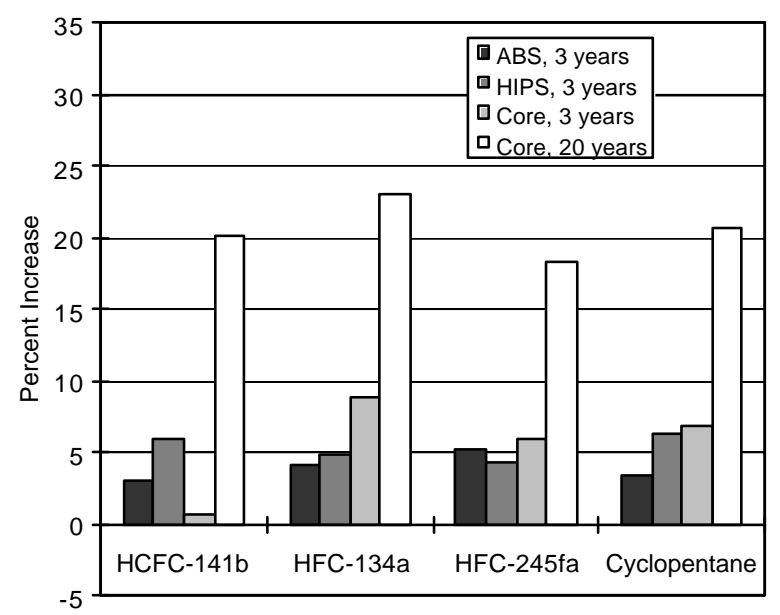

(e) Aged at $-10^{\circ} \mathrm{F} ;$ tested at $75^{\circ} \mathrm{F}$
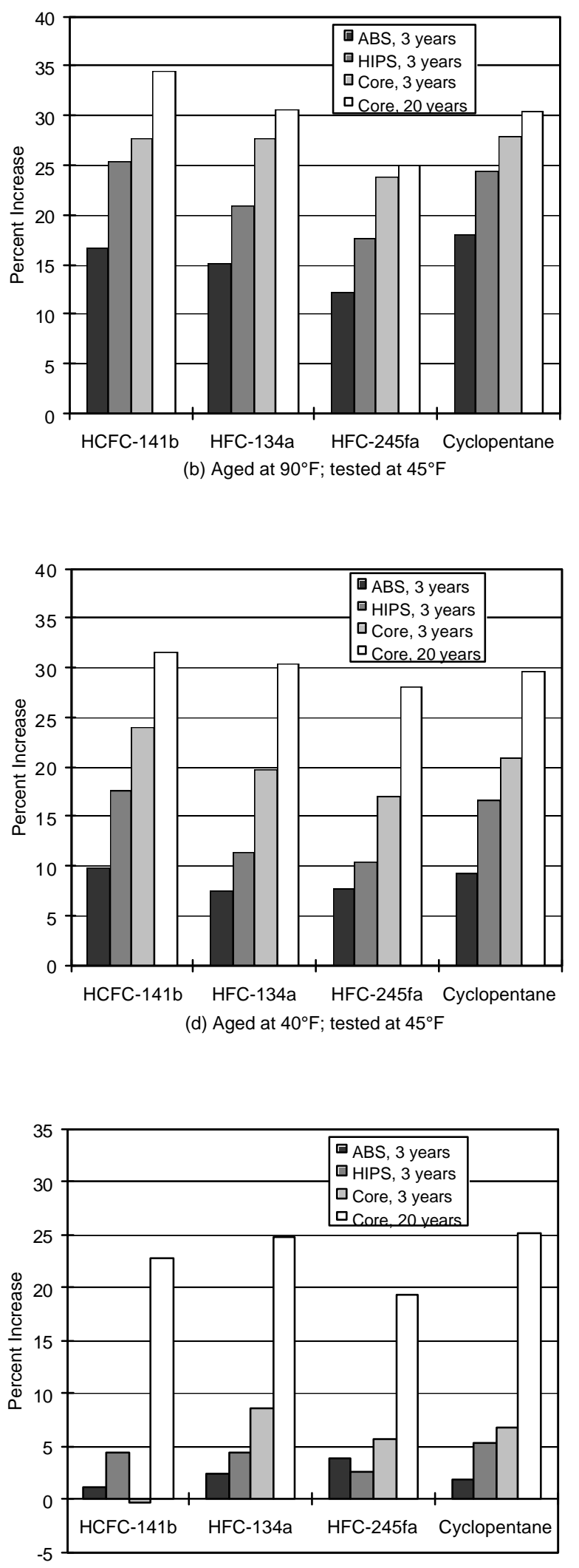

(f) Aged at $-10^{\circ} \mathrm{F}$; tested at $45^{\circ} \mathrm{F}$

Figure 4. Percentage increase in thermal conductivity of foam in full-thickness panels after three years of aging. The legend shows the surface material: ABS or HIPS plastic sheets. Values for panels are averages over four foam suppliers. Values for 
core foam are scaled from aging curves for slices of foam from Supplier $A$. 
surface sheet, and the plus and minus signs on the left hand side of Equation 2 apply to the right and left hand sides of the panel, respectively. The model has been formulated to allow for different permeances on each side of the panel. The surroundings were taken to consist of nitrogen and oxygen at concentrations that correspond to 0.21 atm for oxygen and 0.79 atm for nitrogen.

Equations 1 and 2 are used to calculate concentrations through the thickness of the specimen during aging. Gas pressure profiles under the thermal test conditions are then calculated from the concentration profiles using the ideal gas law and the vapor pressure curve for the blowing agent. Next, the Lindsay-Bromley formulation of the Wassiljewa equation is used to calculate the thermal conductivity of the gas mixture as a function of position through the specimen [10]. The Wassiljewa equation is

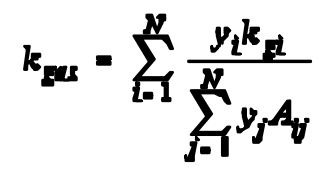

where $\mathrm{k}_{\mathrm{gas}}$ is the thermal conductivity of the gas mixture, $\mathrm{k}_{\mathrm{gi}}$ and $y_{i}$ are the thermal conductivity and mole fraction of the $i^{\text {th }}$ gas, and $\mathrm{A}_{\mathrm{ij}}$ is given by the Lindsay-Bromley equation,

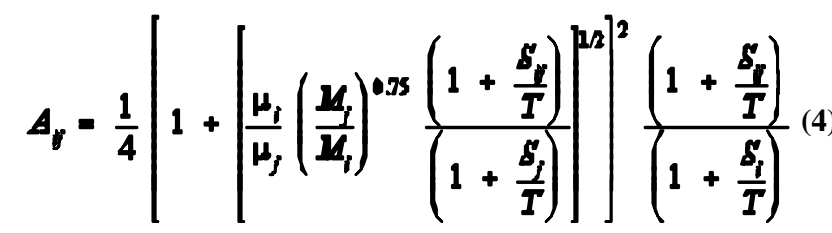

where $?_{\mathrm{i}}, \mathrm{M}_{\mathrm{i}}$, and $\mathrm{S}_{\mathrm{i}}$ are the dynamic viscosity, molecular weight, and Sutherland constant for the $\mathrm{f}^{\mathrm{th}}$ gas, and $\mathrm{T}$ is the absolute temperature. Also, $\mathrm{S}=1.5 \mathrm{~T}_{b i}$, where $\mathrm{T}_{\text {bi }}$ is the normal boiling point of the $i^{\text {th }}$ gas, and $S_{i j}=\left(S_{i} S_{j}\right)^{1 / 2}$ for nonpolar gases. Gas properties needed for specimens blown with HCFC-141b are given in Table 3.

The total apparent thermal conductivity, $\mathrm{k}$, at a plane within the specimen is then calculated from the equation given by Glicksman [16] as

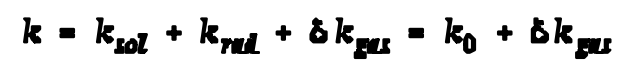

where $\mathrm{k}_{\mathrm{sol}}$ represents conduction through the solid polymer cell walls and struts, $\mathrm{k}_{\mathrm{rad}}$ represents radiation through the foam, ? is the void fraction (taken to be about 0.97), and $\mathrm{k}_{\mathrm{gas}}$ is the thermal conductivity of the gas mixture. Glicksman gives formulae for estimating the values of $\mathrm{k}_{\mathrm{sol}}$ and $\mathrm{k}_{\mathrm{rad}}$; however, for the purposes of this study, their sum is estimated from the measured thermal data. The average thermal conductivity of the specimen is then calculated from an integral over the thickness (L) of the specimen,

$$
k_{\text {mg }}=\left[\frac{1}{I} \int_{0}^{2} \frac{1}{k(x)} d x\right]^{-1}
$$

\section{Material Properties for Model}

In addition to properties of the diffusing gases, the model requires values of the effective diffusion coefficients for the foam and gas permeances for the surface sheets. Permeances of $\mathrm{CO}_{2}, \mathrm{O}_{2}$, and $\mathrm{N}_{2}$ through specimens of the 0.040 in.-thick ABS and HIPS plastic sheets were measured by a commercial laboratory [17], and the results are given in Table 4. These results show that the permeances for HIPS are four to six times larger than for ABS, and that the permeances at 40 ?F were 0.4 to 0.7 of the $90 ? \mathrm{~F}$ values. Diffusion coefficients of gases through specimens of the foam insulation are in the process of being measured using a gravimetric method that was developed by Booth [18]. Data that have been obtained to date are given in Table 5. The large differences among the gases should be noted with both the permeances and diffusion coefficients being ordered as $\mathrm{CO}_{2}>\mathrm{O}_{2}>\mathrm{N}_{2}$. Table 5 also shows that the diffusion coefficient of $\mathrm{CO}_{2}$ through foam blown with cyclopentane is about three times larger than through foam blown with HCFC-141b. This is presumably due to differences in foam structure with the different blowing agents.

Values of the diffusion coefficients and permeances at temperatures other than those at which values were measured were estimated from a fit of the data to the Arrhenius equation, as, for example,

$$
D=D_{0}=-\frac{1}{D T}
$$

\section{Comparison of Model with Data}

Figure 5 compares model predictions with measured thermal data for the thinner slices of core foam blown with HCFC141b. Here, the thermal conductivity is plotted versus the square root of the aging time in order to expand the early parts of the plots where changes are large and to compress the later parts where changes are smaller.

The comparisons in Figure 5a are based on the minimum number of adjustable parameters. In addition to the parameters given above, the model used only two other adjustable parameters. These are the coefficient of diffusion for HCFC-141b, and the sum of the radiative and solid contributions to the thermal conductivity $\left(k_{0}\right.$ in Eq. 5). For aging of the thinner slices at $90 \mathrm{PF}$, the model predicted that diffusion of all gases except HCFC-141b had been completed by about 300 days. After this, the slight increase in thermal conductivity is due to loss of the blowing agent. By a trial 
and error process, a diffusion coefficient of about $2.5 \times 10^{-10}$

$\mathrm{cm}^{2} / \mathrm{s}$ was found to provide a good match for the data.

\begin{tabular}{|lcccc|}
\hline \multicolumn{4}{c|}{ Table 3. Gas Properties for Calculation of Thermal Conductivity of Gas Mixture at 75?F } \\
\hline & $\begin{array}{c}\text { Thermal } \\
\text { Conductivity, } \\
\text { Btu•in./h• } \mathrm{ft}^{2} \text { ? } \mathrm{F}\end{array}$ & $\begin{array}{c}\text { Viscosity, } \\
\text { centipoise* }\end{array}$ & Molecular Weight & $\begin{array}{c}\text { Normal Boiling } \\
\text { Point, K }\end{array}$ \\
\hline Nitrogen & $0.178[11]$ & 0.0174 & $28.01[14]$ & $77.4[15]$ \\
Oxygen & $0.179[11]$ & 0.0200 & $32.00[14]$ & $90.2[15]$ \\
Carbon dioxide & $0.115[12]$ & 0.0148 & $44.01[14]$ & $194.7^{\star *}[15]$ \\
HCFC-141b & $0.067[13]$ & 0.0102 & $116.95[14]$ & $305.2[15]$ \\
\hline
\end{tabular}

* Estimated by Corresponding-States method [14].

${ }^{* *}$ Normal sublimation point.

\begin{tabular}{|c|cccc|}
\hline \multicolumn{6}{|c|}{ Table 4. Permeances of Gases through 0.04-in.-thick ABS and HIPS Plastic Sheets } \\
\hline \multirow{2}{*}{ Gas } & $40 ? \mathrm{~F}$ & $90 ? \mathrm{~F}$ & $40 ? \mathrm{~F}$ & $90 ? \mathrm{~F}$ \\
\cline { 2 - 5 } & 55.6 & 82.9 & 8.78 & 13.6 \\
$\mathrm{CO}_{2}$ & 8.47 & 16.2 & 1.92 & 4.32 \\
$\mathrm{O}_{2}$ & 1.64 & 3.58 & $<0.32$ & 0.78 \\
$\mathrm{~N}_{2}$ & & & & ABS \\
\hline
\end{tabular}

Units are cc(STP)/100 in. ${ }^{2} \cdot$ atm $\bullet$ day

Table 5. Coefficients of Diffusion of Gases through Foam Produced by Supplier A

\begin{tabular}{|lccc|}
\hline \multicolumn{4}{|c|}{ Table 5. Coefficients of Diffusion of Gases through Foam Produced by Supplier A } \\
\hline Foam Blowing Agent & Diffusing Gas & $77 ? \mathrm{~F}(25 ? \mathrm{C})$ & $104 ? \mathrm{~F}(40 ? \mathrm{C})$ \\
\hline Cyclopentane & $\mathrm{CO}_{2}$ & $2.69 \times 10^{-6}$ & $4.52 \times 10^{-6}$ \\
HCFC-141b & $\mathrm{CO}_{2}$ & $8.15 \times 10^{-7}$ & $1.40 \times 10^{-6}$ \\
HCFC-141b & $\mathrm{O}_{2}$ & $3.30 \times 10^{-7}$ & $5.03 \times 10^{-7}$ \\
HCFC-141b & $\mathrm{N}_{2}$ & $1.77 \times 10^{-8}$ & $3.14 \times 10^{-8}$ \\
\hline
\end{tabular}

Units are $\mathrm{cm}^{2} / \mathrm{s}$ 
Figure 5. Comparison of model predictions with measured data for thin (0.4 in. thick) specimens of foam blown with HCFC$141 \mathrm{~b}$ from Supplier $A$. Symbols are measured data; lines are model predictions. (a) Model with minimum of adjustable parameters; (b) with initial $\mathrm{CO}_{2}$ concentration reduced by factor of three and $D$ for $\mathrm{O}_{2}$ reduced by a factor of four.

(Gravimetric measurements are underway to provide an independent estimate of this parameter.) For other temperatures, the ratio of diffusion coefficients for the blowing agent and nitrogen was assumed to be the same as at 90 ?F. This assumption is not critical, since the importance of diffusion of the blowing agent decreases markedly with decreasing aging temperature, due partly to a decrease in the diffusion coefficient, but also due to a large decrease in blowing agent gas pressure because of condensation. Variation of $\mathrm{k}_{0}$ shifts the curves up and down, but does not change their shape. Values of 0.065, 0.066, and 0.061 $\mathrm{Btu} \cdot \mathrm{in} . / \mathrm{h} \bullet \mathrm{ft}^{2} \bullet$ ? were used for the comparisons shown in Figure 5 for aging at $90 \mathrm{PF}, 40 \mathrm{FF}$, and $-10 \mathrm{PF}$, respectively. This comparison shows that with a minimum of adjustable parameters, the model predicts the long-term aging of core foam very well, but further refinements are needed at short times.

Two other parameters were varied to improve the comparison of the model with the data as shown in Figure $5 \mathrm{~b}$. The initial $\mathrm{CO}_{2}$ content was arbitrarily reduced by a factor of three in order to match the model with the data at zero time. Also, the diffusion coefficient for $\mathrm{O}_{2}$ was reduced arbitrarily by a factor of four in order to provide a better match at short times. Neither of these changes influenced the long-term aging predictions, and both changes may be thought of as ways to calibrate the model to the data on the core foam.

The model as calibrated in Figure $5 \mathrm{~b}$ was used to predict the increases in thermal conductivity for the full-thickness panels blown with HCFC-141b. The model simulations included a period of time between the production of the foam

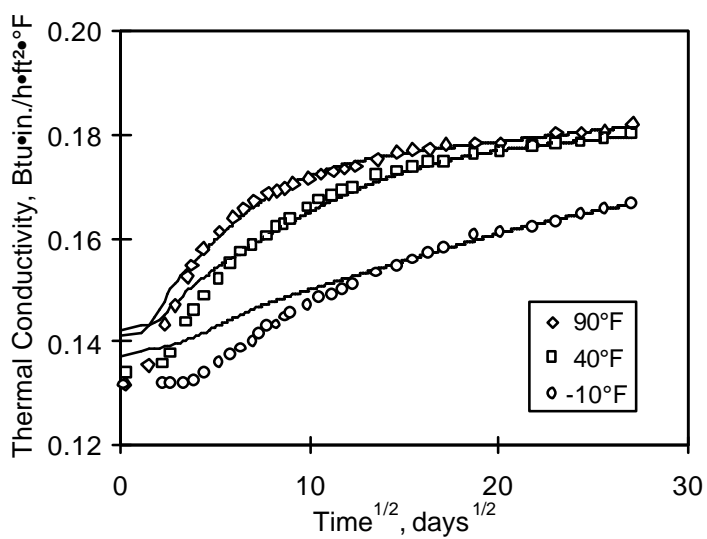

(a)

and the start of controlled-temperature aging, during which the panels were stored near room temperature. Figure 6a shows that the model predicts the aging of the panels with ABS surface sheets very well. Aging of the panels is controlled mostly by diffusion of $\mathrm{CO}_{2}, \mathrm{O}_{2}$, and $\mathrm{N}_{2}$, with very little change in the concentration of blowing agent over this time period.

Figure $6 \mathrm{~b}$ shows a similar comparison for the panels with HIPS surfaces. The agreement between the model and data is good at $40 ? \mathrm{~F}$ and $-10 ? \mathrm{~F}$. At $90 ? \mathrm{~F}$, there is good qualitative agreement, but the model underpredicts the aging by several percent. The agreement could be improved by allowing the gas permeances to be adjustable parameters. Comparisons on more panels, and over a longer time period are needed for a more thorough assessment of the adequacy of the model for predicting long-term aging of panels.

Physical arguments suggest that the time to produce a given change in thermal conductivity would be two to four times longer when one plastic sheet is replaced with a steel sheet. The factor of two would apply if the permeance of the plastic sheets were the dominating resistance to gas transport, while the factor of four would apply if diffusion through the foam were the dominating resistance. The model was used to estimate the effect of a steel sheet on one side. For HIPS on one side and steel on the other, the model estimated that a time period about 3.0 to 3.3 times longer would be needed to produce the same change as with HIPS on both sides. Similar simulations for ABS gave a factors of 2.2 to 2.7. These results show that for HIPS, the gas transport is controlled approximately equally by permeation through the plastic sheets and by diffusion through the foam. For ABS, gas transport is controlled more by permeation through the plastic sheets.

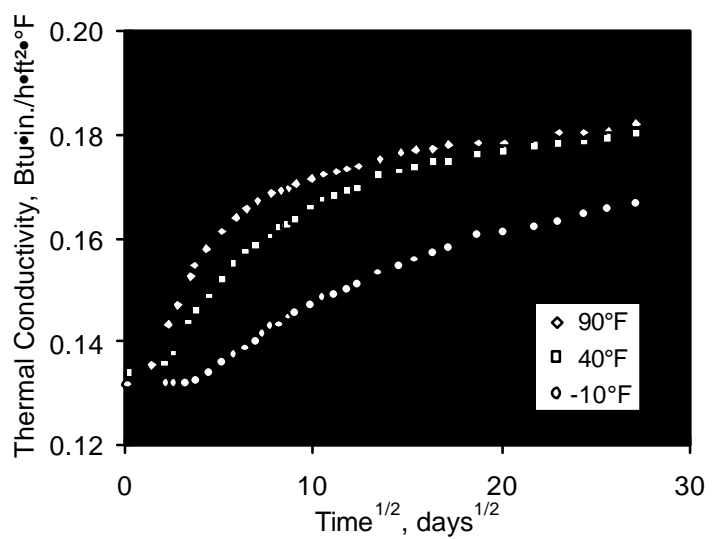

(b)

\section{SUMMARY AND CONCLUSIONS}

Thermal conductivity measurements have been performed over a three year period on a set of full-thickness panels 
containing polyurethane foam confined between solid sheets of ABS and HIPS plastics. The panels simulated the walls and doors of a refrigerator or freezer except that the steel sheet normally on one side was replaced with a plastic sheet.

Figure 6. Comparison of model predictions with measured data for full-thickness panels containing foam blown with HCFC$141 \mathrm{~b}$ from Supplier $A$. Symbols are measured data; lines are model predictions.

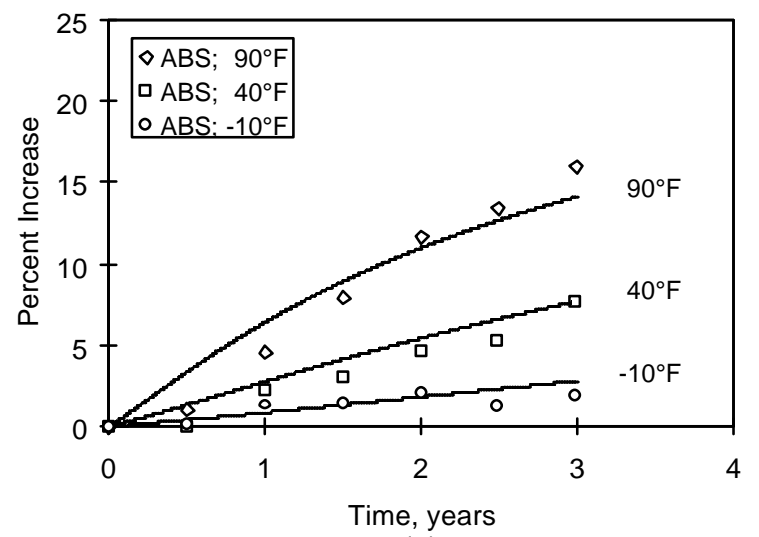

(a)

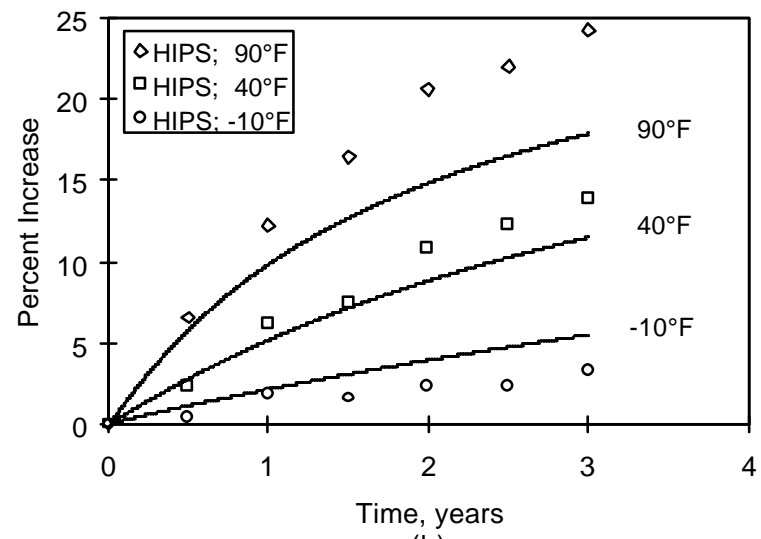

(b) 
Measurements at 75 ?F before the start of controlled temperature aging showed that the conductivity of foam blown with HFC-134a, HFC-245fa, and cyclopentane averaged $18 \%, 7 \%$, and $15 \%$, respectively, higher than that with HCFC$141 \mathrm{~b}$.

Tests on the panels after three years of aging at controlled temperatures have been completed. For both ABS and HIPS plastics, the conductivity increases were less than those predicted for unenclosed full-thickness core-foam, showing that the plastic liners reduce the rate of aging. The panels with HIPS sheets showed average increases of 17 to $26 \%$ with aging at $90 ? \mathrm{~F}, 10$ to $19 \%$ at $40 ? \mathrm{~F}$, and 2 to $6 \%$ at $-10 ? \mathrm{~F}$. The panels with ABS sheets showed smaller increases of 12 to $18 \%$ at $90 ? \mathrm{~F}, 7$ to $12 \%$ at $40 ? \mathrm{~F}$, and 1 to $5 \%$ at $-10 ? \mathrm{~F}$. These differences in aging rates correlate with measurements of gas permeances of the plastic sheets. The percentage increases for HFC-245fa tended to be somewhat less than for the other blowing agents.

Thermal conductivity measurements have been made over a two year period on cut slices of polyurethane foam insulation blown with HCFC-141b, HFC-134a, HFC-245fa, and cyclopentane. Initial results at 75 ? mean temperature before aging showed that the thermal conductivities of foam

blown with HFC-134a, HFC-245fa, and cyclopentane were $21 \%, 4 \%$, and $13 \%$, respectively, higher than with HCFC-141b. The aging rate was sensitive to aging temperature, with aging at 40 ?F being about one-half as fast as at 90 ?F, and with aging at $-10 ? \mathrm{~F}$ being about one-tenth as fast. The relative ranking of the blowing agents was generally preserved through the aging process.

Preliminary comparisons of a mathematical model with aging data show that the model is capable of predicting the aging behavior of thin slices of core foam very well. The model is also able to give good qualitative predictions of the aging of full-thickness panels with solid plastic surfaces. In most cases, very good quantitative agreement was obtained between the model and the full-thickness data. Comparisons on more panels, and over a longer time period are needed for a more thorough assessment of the adequacy of the model for predicting long-term aging of panels.

\section{ACKNOWLEDGMENTS}

The authors would like to acknowledge the contributions of a number of organizations. Funding for this project was provided by the Appliance Research Consortium, the U. S. Environmental Protection Agency, and the U.S. Department of Energy, Office of Building Technology, State, and Community Programs under contract number DE-AC0500OR22725 with the Oak Ridge National Laboratory, managed by UT-Battelle, LLC. Test panels were fabricated by BASF Corp., Bayer Corp., Dow Chemical Corp., and Huntsman Polyurethanes, Inc. Aging chambers were contributed by Sub-Zero Corp.

\section{REFERENCES}

1. Wilkes, K.E., D. W. Yarbrough, and F. J. Weaver. 1997. "Aging of Polyurethane Foam Insulation in Simulated Refrigerator Walls," International Conference on Ozone Protection Technologies, pp. 253-262.

2. Wilkes, K. E., W. A. Gabbard, and F. J. Weaver. 1998. "Aging of Polyurethane Insulation Foamed with Second- and Third-Generation Blowing Agents," Proceedings of the 49th Annual International Appliance Technical Conference, pp. 387-398.

3. Wilkes, K. E., W. A. Gabbard, and F. J. Weaver. 1998. "Aging of Polyurethane Foam Insulation in Simulated Refrigerator Panels - Initial Results with Third-generation Blowing Agents," The Earth Technologies Forum, pp. 280 289.

4. Wilkes, K. E., W. A. Gabbard, and F. J. Weaver. 1999. "Aging of Polyurethane Foam Insulation in Simulated Refrigerator Panels - One-Year Results with Third-generation Blowing Agents," The Earth Technologies Forum, pp. 303313.

5. Wilkes, K. E., W. A. Gabbard, F. J. Weaver, and J. Richard Booth. 2000. "Aging of Polyurethane Foam Insulation in Simulated Refrigerator Panels - Two-Year Results with Thirdgeneration Blowing Agents," Polyurethanes 2000, p. $417-$ 428.

6. C 518, "Standard Test Method for Steady-State Heat Flux Measurements and Thermal Transmission Properties by Means of the Heat Flow Meter Apparatus," in 2000 Annual Book of ASTM Standards. West Conshohocken, PA: American Society for Testing and Materials, Vol. 04.06, pp. 173-184.

7. Haworth, G. J. 1996. "Next Generation Insulation Foam Blowing Agents for Refrigerators/Freezers," Proceedings, 47th International Appliance Technical Conference, pp. 271-282.

8. C 1303, "Standard Test Method for Estimating the LongTerm Change in the Thermal Resistance of Unfaced Rigid Closed Cell Plastic Foam by Slicing and Scaling Under Controlled Laboratory Conditions," in 2000 Annual Book of ASTM Standards. West Conshohocken, PA: American Society for Testing and Materials, Vol. 04.06, pp. 726-734.

9. Hoogendoorn, C. J. 1994. "Thermal Ageing," in Low Density Cellular Plastics: Physical Basis of Behaviour, N. C. Hilyard and A. Cunningham, eds. London: Chapman \& Hall, pp. 153-186. 
10. Reid, R. C. and T. K. Sherwood. 1966. The Properties of Gases and Liquids, 2nd Ed. New York: McGraw-Hill, pp. 483-484.

11. ASHRAE Handbook-Fundamentals. 1997. Atlanta: American Society of Heating, Refrigerating, and AirConditioning Engineers, pp. 19.75-19.79.

12. Eckert, E. R. G. and R. M. Drake, Jr. 1959. Heat and Mass Transfer. New York: McGraw-Hill, p. 506.

13. Shankland, I. R., D. J. Williams, M. C. Bogdan, and P. B. Logsdon. 1998. "Next Generation Blowing Agents for Thermal Insulating Foams," in 60 Years of Polyurethanes, J. E. Kresta, E. W. Eldred, eds. Lancaster, PA: Technomic Publishing Co., Inc., p.86.

14. Reid, R. C. and T. K. Sherwood. 1966. The Properties of Gases and Liquids, 2nd Ed. New York: McGraw-Hill, p. 405.

15. ASHRAE Handbook-Fundamentals, 1997. Atlanta: American Society of Heating, Refrigerating, and AirConditioning Engineers, p. 18.3.

16. Glicksman, L. R. 1994. "Heat Transfer in Foams," in Low Density Cellular Plastics: Physical Basis of Behaviour, N. C. Hilyard and A. Cunningham, eds. London: Chapman \& Hall, pp. 105-152.

17. Permeance measurements were made by Modern Controls, Inc., Minneapolis, Minnesota.

18. Booth, J. R., R. S. Graves, and D. W. Yarbrough. 1996. "Effective Diffusion Coefficients for CFC-11 by Gravimetric Depletion from Thin Slices of PIR Foams," in Thermal Conductivity 23, K. E. Wilkes, R. B. Dinwiddie, and R. S. Graves, eds. Lancaster, PA: Technomic Publishing Co., Inc., pp. 352-337.

\section{BIOGRAPHIES}

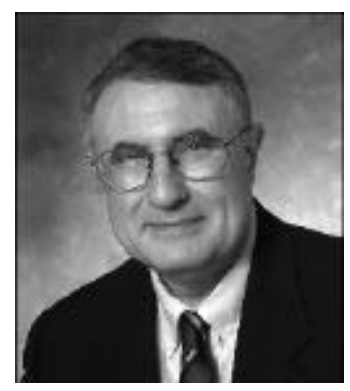

\section{Kenneth E. Wilkes}

Ken Wilkes is a senior research staff member at the Oak Ridge National Laboratory (ORNL). He holds a B.S. in Mechanical Engineering from Duke University, an M.S. in Mechanical Engineering from Purdue University, and a Ph.D. in Condensed Matter Physics from The Ohio State University. $\mathrm{H}$ has performed research on thermal insulation for over 20 years. $\mathrm{He}$ is a registered

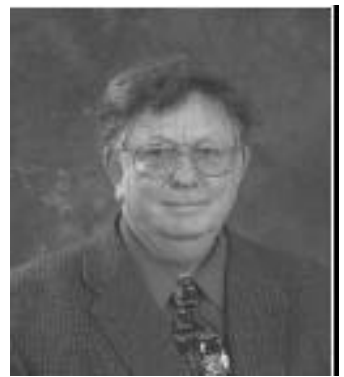
professional engineer and is active in ASTM Committee C 16 on Thermal Insulation.

\section{David W. Yarbrough}

David Yarbrough is an adjunct research participant at ORNL and also Professor and Chairman of the Chemical Engineering Department at Tennessee Technological University (TTU) He earned B.Ch.E., M.S., and Ph.D. degrees in chemical e $n \mathrm{~g}$ i n e e ring from the $\mathrm{G}$ e or g i a Institute of Technology. He has

over 20 years of experience in thermal insulation research, is

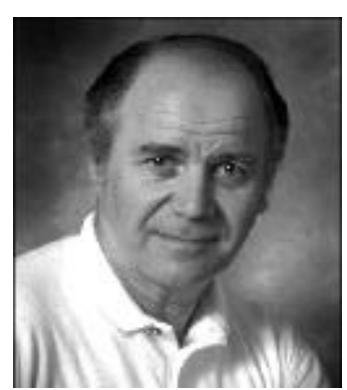
active in ASTM Committee C 16, and is a registered professional engineer.

\section{W. Alex Gabbard}

Alex Gabbard is a research staff member at ORNL. He received his B.S. and M.S. in physics at North Carolina State University. He has been at ORNL since 1980 and has worked on programs dealing with thermonuclear fusion, nuclear fuels, carbon, and thermal insulation.

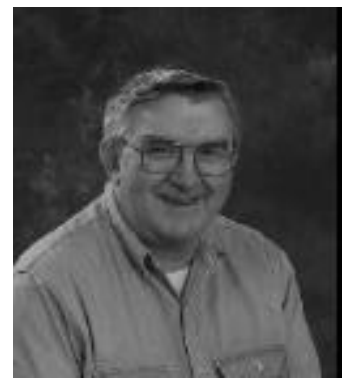

\section{Gary E. Nelson}

Gary Nelson is a research technician at ORNL. He has been at ORNL and the Oak Ridge Y-12 Plant for 25 years, where he has worked in analytical chemistry and physical properties measurements.

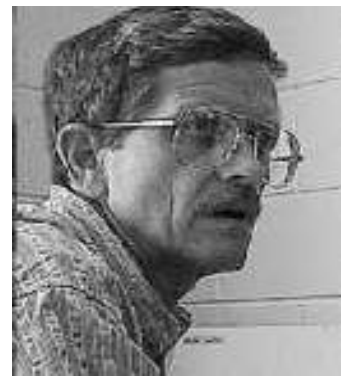

\section{J. Richard Booth}

Richard Booth received his B.S. from Virginia Polytechnic Institute and State University and his M.S. and Ph.D. from Clemson University, all in chemical engineering. $\mathrm{He}$ worked for Dow-Badische and the Dow Chemical Company until 1994. He is currently an Adjunct 
A s sociate Professor of Chemical Engineering at TTU. He has performed research on the properties of foam insulation for over 20 years. 